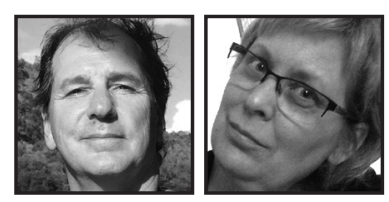

\title{
Addressing "Who Are You as a Scholarly Professional?" Through Artful and Creative Engagement
}

\author{
Tim Molnar and Heather Baergen, University of Saskatchewan
}

\begin{abstract}
This work offers examples and discussion of the work of participants in a graduatelevel education course where creative engagement and meaningful learning through artful inquiry were pursued in addressing the question, "Who are you as a scholarly professional?" We provide a brief description of the nature of coursework, followed by descriptions of participants' work, and the authors' experiences as graduate student and instructor in creating a Visual Journal and conducting the experience, respectively. There is a discussion of the motivations, challenges, and outcomes experienced by the authors as they seek to create meaningful and transformative learning experiences for themselves and others.
\end{abstract}

n talking of learning that is transformational or deeply meaningful, Mezirow (1997) described a process where there is change in an individual's "frame of reference ... associations, concepts, values, feelings, conditioned responses-frames of reference that define their life world" (p. 5, emphasis in original); a change that is inclusive, discriminating, self-reflective, and integrative of human experience. For educators this is a desirable and elusive goal as they plan for the development of such understanding. Schlechty (2002) suggests, "engaged students see meaning in what they are doing ... When students are ... engaged, the distinction between ends and means become blurred" (p. 10). This blurring of ends and means shows, as Fredricks, Blumenfeld, and Paris (2004) outlined, that engagement is a complex, multi-faceted meta-construct that involves behavioural, emotional, and cognitive aspects. With such engagement creativity is always at play, for both learner and instructor, who further develop their knowledge and understanding. 
This work offers examples and discussion of the challenges and experiences in a capstone course for course-based Master's students, where we believe creative engagement and meaningful learning through artful inquiry were realized. We believe this experience is one where participants have the opportunity to go beyond conditioned or typical responses and involves expanding participants' frames of reference and in doing so, they are creatively engaged in an artful inquiry. To gain some perspective on this experience we offer a brief description of the nature of coursework. We provide some description of participants' work as examples of creative engagement through artful inquiry, and we provide information and discussion relating to what transpired for each of us as scholarly professional and instructor. We conclude by outlining what we believe are factors, both emergent and explanatory, that are entangled with an artful and creative graduate-level experience.

\section{The Nature of the Learning Experience}

Later in this work Heather will detail her experience and efforts in creating a Visual Journal as one example of artful inquiry through creative engagement. First, however, we will provide a course description and some examples of participants' work to provide a sense of the creativity, artfulness, and diversity involved in those efforts.

Typically, those enrolled in this course are experienced teachers, usually mid-career, who for various reasons have foregone a thesis or project route and require this final course as a synthesis or "capstone" to their Master's experience.

Initial versions of the course envisioned people participating in online discussion forums and in-class discussions. Individuals were to deliver a presentation based on a "final" paper and engage in a final oral examination. Through these activities, participants were to analyze their work and effort in previous master's courses, read additional articles as required, and arrive at a final synthesis of understanding of their Master's experience. Each of these was to be assessed by the instructor using a standard set of assessment measures.

These activities have remained possible course paths. However, over several course iterations a more eclectic, creative, and wide-ranging process of engagement has emerged, guided by a singular question: "Who are you as a scholarly professional?" In the context of this paper, course participants wrestle with and address this question over the 13-week course using their previous master's course experience as a crucial 
part of that meaning making. Participants are invited and encouraged to develop or employ skills, technologies, and mediums new to them or to reengage those that might have fallen out of use over time. Repeatedly emphasized are that participant's experience of meaning making is as much about the process as the product that emerged from their efforts. The students are invited to create a portfolio, paper, performance, play... anything employing the resources, abilities, and skills they decide to employ or develop. Emphasized as well is the celebratory experience of learning, and the opportunity to push personal boundaries in addressing the essential question. The use of metaphor as a guide for framing understanding is encouraged, as well as acknowledging and acting upon the reality that our professional and personal lives are influencing each other continuously. At its core, this course concerns people addressing their experience: past, present, and future.

There is a temptation perhaps to classify participants' efforts as more or less traditional in the context of a graduate course. We leave to the reader such determinations. However, we remain intrigued by the efforts of participants who choose to push boundaries in both the process and the products. Some responses to this course are indeed traditional in format, which is not to downplay them, for they are full of meaning, have utility for the participant and, in meeting the course requirements, are what the scholarly professional chose. These are equally encouraged.

The range of works produced have included such processes and products as musical composition and performance, video production (i.e., autobiography, interviews), photo essays, poetry and art galleries, electronic portfolios using applications such as Mahara $^{\mathrm{TM}}$, oil paintings, academic papers, character portraits (pencil sketch and story), PowerPoint $\odot$ presentations, sculpture, banquet as metaphor and lived experience, creating board games and puzzles, Prezi ${ }^{\mathrm{TM}}$ and Wordle ${ }^{\mathrm{TM}}$ presentations, 3D models, letters to significant others, yoga session, crafted artefacts (i.e., medicine wheel, beaded moccasins) and scrapbooking. Other participants have produced professional development packages, dossiers, research posters, and websites and engaged in digital storytelling. Typically, participants have shared with each other a verbal accounting of and a reflection on their efforts, whether this was during the scheduled end-of-course sharing days, or in another agreed upon venue, such as the college's Celebration of Research Conference.

One intriguing outcome involved a participant employing oil painting as a process of reflection. Janeen (a pseudonym) decided to renew her lifelong passion for oil painting. She re-created the painting by the French artist Paul Gauguin entitled, "Where Do We Come From? What Are We? Where Are We Going?" This famous painting addresses 
the fundamental human condition through three scenes depicting Tahitian people in various stages of life and repose. Janeen reinterpreted this famous image through her artistic endeavour to develop an understanding of herself as a scholarly professional. In her painting she inserted a variety of quotations and ideas from her personal, professional, and academic experience. Interestingly enough, Gauguin relates that the white bird he painted accompanying an aging woman near death represents the futility of words to represent the reality of humanity. This message is perhaps a shared belief that even in the academic world to begin to understand one's self and roles we must go beyond what words alone can convey.

\section{A Participant's Experience}

To provide further insight into the experience of addressing oneself as a scholarly professional, Heather shares her experience of artful inquiry in the following section:

I was a graduate student while also working at the university as a seconded teacher. I had left my rural Saskatchewan primary classroom teaching position of almost 20 years to move to Saskatoon as an instructor in the teacher education program. My work there included teaching courses and supervising pre-service teachers during their internship. It was challenging, demanding, and ultimately rewarding work that provided for me the impetus to examine my own beliefs about education as well as the experiences that had led me to those beliefs. After three years in this rich learning environment, I walked into my final capstone course curious about the expectations. I was cautiously ready for this new challenge.

The capstone course did not impose the parameters of my previous graduate classes. I described the course outline to the art instructor next door to my office and she immediately suggested that I try a Visual Journal. Intrigued, I accompanied her to her studio where she gave me a few books for inspiration. Having decided to go for it, I went over to the campus bookstore to buy a sketchbook, markers, paints, pencil crayons, and glue. I gave myself the freedom to fill the initial pages of my Visual Journal with "Where did I come from?" and in so doing, I embedded the entire process in my childhood and early professional life. It became increasingly important to me to own this representation of learning. I found the work deeply personal. The capstone had given me a learning opportunity that would ultimately be for no one else, really, but for me (see Figure 1). 


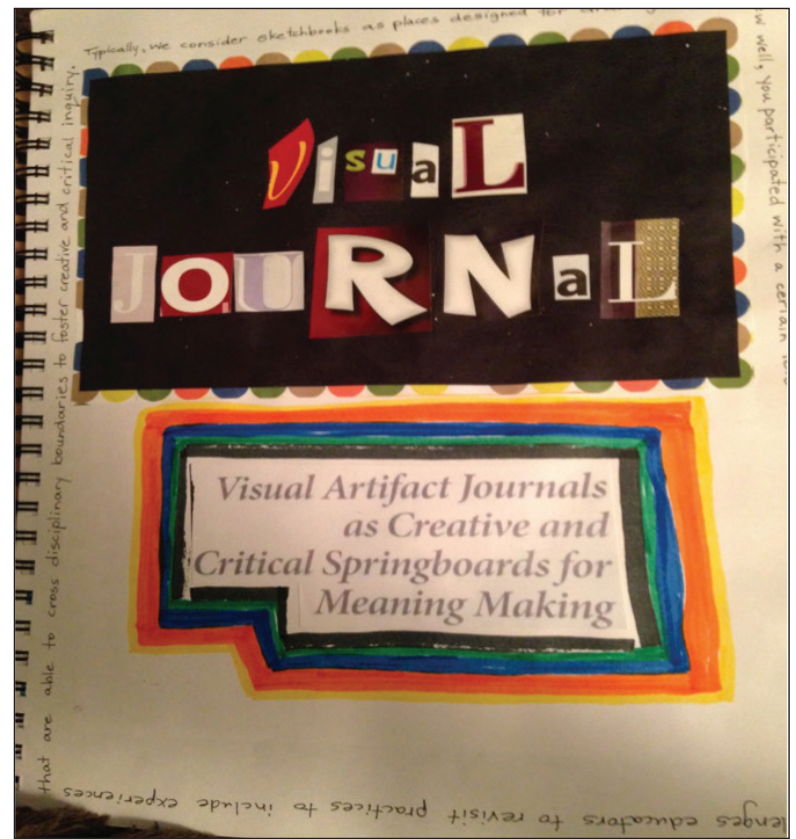

Fig. 1: A visual journal

The Visual Journal became an invitation to slow down and to grapple with the ideas that I had encountered in each one of my previous classes. I spent a lot of time just sitting and wondering. The big comfy chair in my office, which visitors often plunked into for a quick chat, and which I later used in the "Celebration of Learning" installation, became a symbol of pushing away from the experts and tentatively moving toward my own ways of knowing. For me, that chair was an integral part of the capstone process.

My attempts at visually representing intellectual understanding became addicting, non-linear, spiral, divergent, and satisfying. The process was a new experience which I found liberating. At times it made me laugh! I didn't need to get anything "just right." What I needed was to let the images emerge from inside of me, to recognize the pictures in my imagination as I reviewed my previous Master's work in the context of my personal and professional life. I found myself hanging on to the part of each image that was uniquely mine, often accompanied with a touch of emotion or the hint of a childhood memory lingering in my mind. Instead of filtering these personal connections and meanings out of the project, I was teasing them into view, trying to capture them from a perspective that was intimately ME. I was synthesizing my learning visually and for some reason that brought with it an expanded understanding beyond the verbal, linear, or rational. 
I decided to intersperse my reflections with "The Story of Jumping Mouse: A Native American Legend," retold and illustrated by John Steptoe. This was done mostly because, as the time for me to leave my students, my school, my town had loomed closer and closer, my students had begun to see me in every book that we read. It seemed that having me leave them for my new work in the city was far more significant than them leaving me for the next grade down the hall. As I thought about the past three years, my students' voices were still with me, sending me along on my own perilous journey saying, "Keep your hope alive, Ms. Baergen. Keep your hope alive." I found their belief in me both comforting and a wee bit daunting.

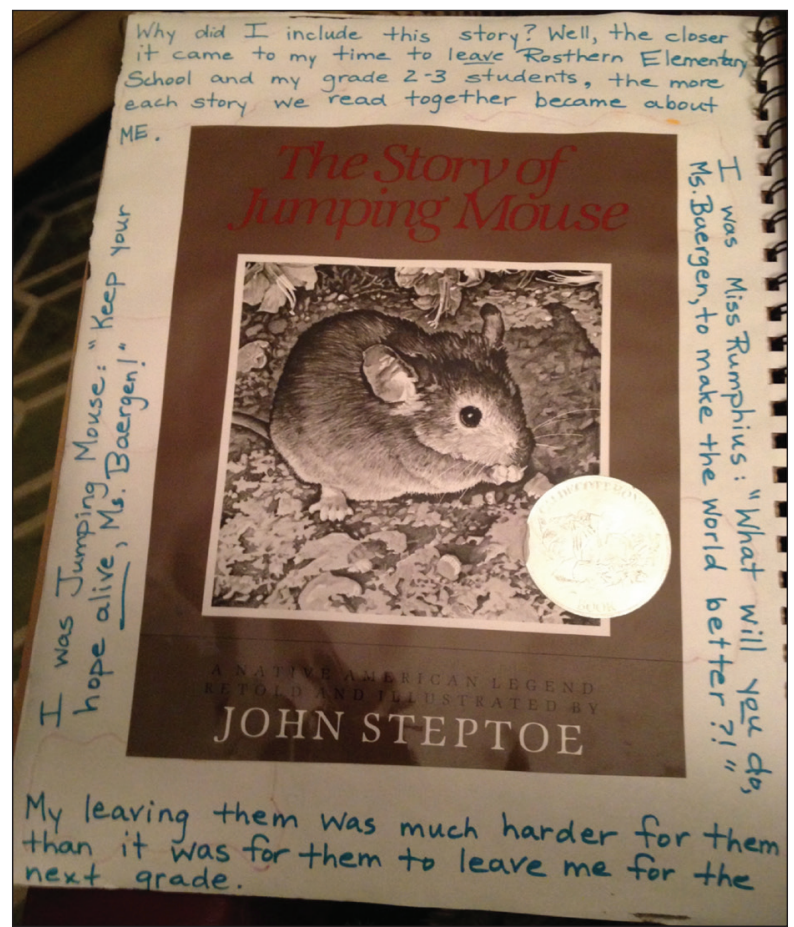

Fig. 2. The story of jumping mouse: Using analogy for reflection

Thinking about my thinking, asking why particular ideas stood out for me while others did not, wondering how all of the pieces fit together...this is what I mulled over as I attempted to create a visual representation for each of my grad classes. I decided to keep track of the time I spent working on the project. I knew how to manage my time when responding textually to my grad classes, but I had no idea how long this would take as I responded visually. As it turned out, it took a lot more time to respond visually, 
but I perceived it to be much less. And instead of surging to the finish line and being relieved to be "done," I was almost unable to pronounce it complete because there was always something more to think about.

When I had worked my way through all of my classes, I began to wonder about the "Now what?" part of my degree. Who was I now as a result of all of these classes? I gave this question lots of time to evolve. Part of this evolution was clarified during a wonderful conversation with another faculty member who specializes in early childhood education. She did not doubt for one second that this was my thesis and that it was worthy of being called research. She helped me to value the Visual Journal as my exploration of what it meant for me to be a teacher in the past, present, and future.

I found this process of artful inquiry powerful and resonant for two reasons. First, I was able to move out of a "productive" mode into a more "receptive" one. This shift was symbolized by the big comfy chair. The capstone course was an invitation to sit and wonder. I spent an unprecedented amount of time reading over old class notes and letting my mind wander, noticing what voices were important to me, following where they might lead, and asking why this might be so; why did I pause at the moments that I did? As each image emerged onto the page before me, I felt as though I was seeing myself in a new way, a way that made room for both me and the authors who had opened doors for me saying, "Come on in; you will like it here."

Second, I did not feel compelled to begin with the ideas of the "other." I always started with me, in spite of the muddle, in spite of uncertainty or a lack of clarity and conviction. This project invited me to wander into the labyrinth of my own tentative beliefs as a result of being exposed to so many ideas over the past three years. In creating a Visual Journal, I was collecting, sorting, sifting, and ultimately making decisions as to what to keep at the end of this process. I learned to anchor myself in my own background knowledge and my unique connections to create a deeply personal statement about who I am as a scholar.

\section{Visual Journaling: A Rigorous Process?}

Sharing the Visual Journal was a mixed experience for me. On one hand, I was awkwardly shy about the "primary school" feel to the final product. It seemed less worthy, less "cutting edge," less scholarly than the on-line and artistic products of my classmates. However, it would not be honest to stop there. I was also delighted and 
curious to see what people would see in this hands-on-cut-and-paste-and-smellymarkered scrapbook. I wondered how this work would be received by my peers and professors. I had come to believe deeply in this way of learning, this step away from the Internet and into my own early learning as a child and more recently as a teacher of noisy, messy, unpredictable, and wonderful primary-aged children. It felt like a challenge thrown into academia from the murky depths of my past experiences.

I signed up to share my work at the upcoming Celebration of Research. As I read the description of the event, I had to take a deep breath and decide if I really wanted to be quite that vulnerable. The description read, "The Celebration of Research and Scholarship is the College's opportunity to showcase the rich, diverse, and high quality work of our graduate and undergraduate students." I was not at all convinced that my work would be welcomed as rich, diverse, or high quality. At the same time, I evangelically believed that it was exactly that! The call for proposals invited "all students regardless of where they are in their program to submit one of the following: a research poster, an oral presentation, a panel presentation, or a roundtable of work-inprogress." It went on to describe what each of these submissions should include. Help?! My project just didn't fit any category...Worse still, my "Mode of Presentation" was a Scrap Book, big comfy chair, and an antique end table with markers and a lamp...?! I submitted my title and held my breath: "Who am I as a scholarly professional? Representation through Visual Journaling."

Feeling like I had somehow snuck past the planning committee, I stood back at the Celebration of Research Event and chuckled to see how many people walked right past my "art installation" version of research. They didn't seem to recognize it as part of the celebration at all. Of those who did stop to have a look, a few sat down and smiled as they flipped through the Visual Journal although, sadly, nobody tried out the markers.

On the way home from the Celebration of Research I was suddenly able to answer the question, "Who am I as a scholar?" I was happy to realize that I ask questions. I am a questioner. I am a wanderer, a collector of images and experiences and stories, a grappler and an experimenter. I do not need answers so much as I need questions. That is who I am. 


\section{An Instructor's Experience}

My experience as a university professor began when I was offered employment as a science educator and began teaching undergraduate methodology courses in science teaching and learning. Previous to this I taught mostly sciences in secondary schools. This change of profession occurred after many years in secondary schools, teaching subjects such as science, biology, chemistry, mathematics, and computer science, all of which typically assess and evaluate students' work in often linear, prescriptive, and formatted ways. However, even earlier in my career I was uncomfortable with the notion of teacher as the sole or predominant "holder" and dispenser of knowledge and expertise, with teacher as sole judge of worthiness, and with the lack of opportunity for students to be creatively engaged in making sense of the world and in representing or sharing what they understood. I agreed teachers should possess significant knowledge and expertise and share this regularly, and that some types of knowledge are best dealt with in certain forms and standards, but I was always interested in the meaningfulness of the experience and knowledge for the learner.

My discomfort became acute when tasked with the capstone course. How was I to evaluate the work of participants? How was I to help them have a meaningful experience? Should I mandate particular formats and inclusions, for example, the development of a dossier noting their work in each course, papers read, articles produced, what was learned from each course and top it off with a final paper? This is not an unworthy approach, yet each person's experience, despite sharing some common courses, instructors, and experiences, would ultimately be very distinct, diverse, and unique. How much should I prescribe and what liberties should I allow given the general nature of participants as seasoned professionals, with their diverse experiences, who most often would continue in their profession? Considering their experience as part of a life path, not only an academic path or a professional path, but also one that existed alongside and interwoven with more personal experience, my hope was for people to truly make the experience meaningful for themselves and for their lives and not exist entirely in academic solitude; a criticism heard often enough concerning universities. For me, education should be something you do and less something that is being done to you; and so questions of what is involved in being educated, who has power and control, the direction of learning, what is demanded as evidence of learning, and how roles play out come forward for consideration. There is not room to deal with each of these considerations in depth here, but I will provide some insight into my thinking as an instructor wrestling with such tensions in trying to be an activator in creatively engaging participants in an artful inquiry into who they are as scholarly professionals. 


\section{Thoughts and Action: Process and Products}

There was an evolution in my practice and thinking as I attempted to create a meaningful learning experience for participants. The development of the single question concerning being a scholarly professional emerged from discussions of participants in early courses. Hoping to better guide decisions about course structure and outcomes and to focus the efforts of participants, I settled on this singular outcome. The intent was to focus attention on a specific outcome while broadening and supporting approaches that participants undertook to understand, represent, and share their knowledge. From initially using dossiers, final paper, and electronic portfolios as the main "vehicles" for both process and as product, I began to widen the possibilities, to also include poster work, performances, and play. When conversing with participants I referred to these as the "P's", paper, poster, portfolio, presentation, performance, and play. Each of the "P's" contained within them a variety of possibilities (i.e., video production as part of an electronic portfolio, musical performance, etc.). The "P's" often overlapped depending on how participants addressed the question. What was important was not delimiting, but liberating participants in their considerations of what was possible, what they might achieve and how it would serve them.

While trying to create opportunities I struggled with concerns for rigor, consistency and fairness. I wrestled with urges to demand students produce an outcome that I might desire, something "normal" in the context of graduate school, while still having this product serve them in achieving their ends for their purposes. In seeking and supporting more diversity in process and product, my thoughts on evaluation had to change and accommodate the wide range of process and products that participants realized. Letting go of my tendencies to consider the written word as the necessary form and the measure of worth, I realized the need to value the process of reflection and crafting in their own right. These processes, unseen to me but surely happening, needed to be acknowledged, respected, honored and given value.

The value of process was emphasized with participants in part by emphasizing the "P's" and emphasizing that the processes of creativity were as important as the product, that in fact the process is a product and is to be equally valued, not just given lip service. This was especially true for those who chose to perform or provide more artistic products in addressing the scholarly professional question. This emphasis on process fit with supporting and encouraging participants to push their boundaries by trying new and different modes of investigation, reflection, meaning making, and sharing. 
However, attending to the process, trying to determine its values, when one is not involved directly in the process, poses a challenge; a final product may be indicative of the process, but not be a reliable indicator of the quality and effort put into the process. This is especially so when individuals attempt something new, where they learn much, but the final product is not realized in the fashion they intended. To mitigate such concerns, participants reported to each other in online forums, and face-to-face in the learning community as well as providing me with short "progress" reports that I requested, as well as direct conversation. These seemed to aid people in progression and provide a level of comfort for participants and myself.

One of the inevitable responsibilities of an instructor in such university course work is to judge and evaluate the quality of that work. Given my desire for participants to risk and explore possibilities, to push boundaries for making sense of their Master's experience and how they understood that experience, concerns about rigor and evaluation soon emerged. Participants come with a wealth of knowledge developed through unique and contextualized experiences, and so subscribing to a singular rubric for evaluation, if too specific and restricting, might work against the creative engagement and artistry participants were encouraged to realize. Compounding this situation was the typically high level of emotional effort and involvement participants experience in the process of making sense of their Master's experience while contextualizing that experience in the broader context of their lives.

Given these challenges I attempted to resolve the tension by de-emphasizing marks, emphasizing the need for learning to be meaningful, that each person's process and product was unique, that there was no singular "correct" path in response to the question of being a scholarly professional, and that process was equally as important as the final sharing product. This meant, for example, moving from a purely instructordetermined evaluation to a more or less negotiated mark employing participant's input using three frames of reference-their current efforts in comparison to their past efforts, their efforts in comparison to that of their peers, and finally a consideration of their effort given their current life situation-and moving from position as the "expert" to being a participant in a group of "experts" (experienced, successful teachers from a variety of contexts, with multiple graduate courses completed) where our group knowledge and insight was superior to any individual.

The artful inquiry into my own practice in offering participants the opportunity to fully and creatively engage themselves emerged in several ways. This included: 
- Rethinking, negotiating, and reconfiguring the power and control dynamics in the course so as to engage graduate students as peers and professionals while renaming and addressing participants not as graduate students, but as scholarly professionals (i.e., be the change you wish to see);

- Moving from strictly focusing on textual and philosophical analysis and representation in relating the reality of participants' lives, personal and professional, and so allowing emotive aspects to be acknowledged and acted upon;

- Scheduling the course into a blended learning environment (on-line and in class) with fewer in-class sessions (providing time for participants to think and work on their own, and interact with other colleagues on-line);

- Broadening the possibilities for how participants came to understand, represent, and share their work through emphasizing the diverse possibilities open to them (i.e., paper, poster, portfolio, presentation, performance, and play);

- Shifting from a more instructor controlled to shared control where the learning community came together, set their terms for engagement, both personally and as a group (my role shifted more to acting as confidante and guide, rather than as judge);

- Responsibility for assessment shifting from instructor centred to one of the learning community and the individual where each person reported his or her progress, challenges, struggles, and successes to the learning community;

- Final evaluative determinations remained the instructor's responsibility, though participants' self-assessment usually stood as the final evaluation (only if participant's self-assessment seemed ill fitting would there be further conversations with the scholarly professional);

- Acknowledging and relying on the scholarly professionals' group knowledge and expertise as more diverse and generative than an instructor's knowledge alone;

- De-apprenticing experienced educators from their apprenticeship in assessment and evaluation by questioning their thinking, experiences, and expectations concerning typical demonstrations of academic excellence, while using the 
university's standards as guides to craft new approaches, and expecting excellence;

- Emphasizing that inquiry is more than a linear, predetermined process; that inquiry is a creative process informed by need, motivation, past experience and personal and societal urgings, and finally and perhaps most importantly;

- Framing the learning experience as a celebration of meaning making interweaving personal, academic, and professional understanding.

\section{Concluding Thoughts}

We suggest the opportunity offered participants in this experience for creatively and artfully engaging in inquiry is entangled with several other factors crucial to meaningful or transformative learning. What emerged in this learning context was a high degree of ownership, perhaps triggered by the significant latitude provided for all participants to address their unique situations, challenges, hopes, and tensions. While more typical approaches were welcome in responding to "Who are you as a scholarly professional?", many took the opportunity to attempt new methods of representation that inevitably led to a fulsome reflection on their experience. Perhaps this was because what was being represented, the representation and meaning making that occurred, was a continual process that both invited and forced the learner to fully engage in making sense (Hoban \& Nielsen, 2010). Having a substantial sense of ownership for process and product while addressing the question of being a scholarly professional and completing their final master's, people appeared to be less concerned with graded outcomes and more concerned with producing something meaningful and helpful to themselves, while meeting course demands, but also positioning them for their future pathways, personal and professional. This high level of ownership in structuring their response spawned genuine and often very inspirational work. The strong sense of ownership seemed to inspire participants to relax their concerns in terms of fulfilling course requirements, attaining a grade, and completing their degree. In this mix of ownership and inspiration, commitment to their work often appeared to deepen. This was evident in the class discussions and in personal discussions where students would report regularly about losing track of time, or having time speed by, as they worked. The outcome for some regularly saw them exceed what they expected to experience in time and effort if their self-assessment and peer assessments are to be trusted. 
Participants developed trust in their ability to attain the challenging goals set for themselves and in the judgment of their colleagues. The attentiveness of the learning community to each other is key in developing such trust. Such trust is crucial if participants are going to challenge the boundaries they normally work within in an academic setting. This trust emerged through the group conversations, sharing circles, and on-line forum sharing. People better understood what they were doing in comparison to what others were attempting, were advised to avoid certain paths or at least to be aware of what would be demanded of them in pursuing a particular process and product. The development of trust through the sharing of experience allowed for participants to take risks they might not initially have felt comfortable considering. This was especially poignant when considerations and discussion of academic rigor came to the forefront. However, questioning the norm of graduate-level teaching and learning, and what is considered normal and how people would negotiate this, inevitably resolved itself for each participant through the discussions and personal sharing among participants. While not always or entirely the case, most people got past their discomfort of operating out of what might be considered the norm for process and product in a graduate-level course, and if not undertaking more boundary-pushing work themselves, supported that of their peers.

As the work of Heather and other participants suggests, creative engagement is a daring inquiry into who people are as scholarly professionals that requires a safe and welcoming learning context where the most deeply felt urges for creativity and sharing can come forward. Such engagement is an opportunity where risk and boundary pushing in making meaning and understanding oneself is supported and encouraged; where the personal, the emotional, the intellectual are purposefully connected, and where the process of inquiry, reflection, and understanding have value in themselves equal to that of any final product. Investigating who you are as a scholarly professional not only involves addressing academic concerns, but also deeply personal ones. In this way such engagement requires opportunities for creative meaning making and sharing for each human being. 


\section{References}

Hoban, G., \& Nielsen, W. (2010). The 5 Rs: A new teaching approach to encourage slowmations (studentgenerated animations) of science concepts. Teaching Science, 56(3), 33-38.

Fredricks, J. A., Blumenfeld, P. C., \& Paris, A. H. (2004). School engagement: Potential of the concept, state of the evidence. Review of Educational Research, 74(1), 59-109.

Mezirow, J. (1997). Transformative learning: Theory to practice. New Directions for Adult and Continuing Education, 74, 5-12.
Schlechty, P. C. (2002). Working on the work: An action plan for teachers, principals, and superintendents. San Francisco: John Wiley \& Sons, Inc.

Steptoe, J. (1984). The story of jumping mouse. New York: Lothrop, Lee and Shephard Books.

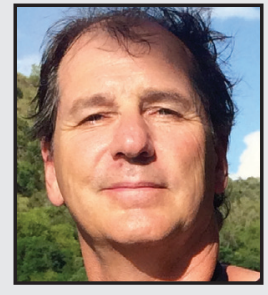

Tim Molnar is a faculty member in the department of Curriculum and Instruction at the University of Saskatchewan. Prior to this he taught for over 20 years in a variety of contexts in public school systems from kindergarten to grade 12 . His teaching and research work involve the areas of science, science education, teacher and technology education, curriculum theorizing, and ethics.

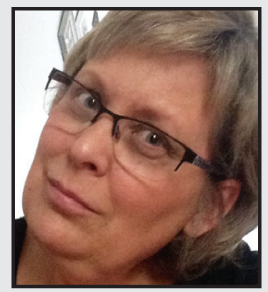

Heather Baergen taught primary school for 15 years in rural Saskatchewan until she was seconded from her school division to the University of Saskatchewan where she worked with pre-service teachers while continuing to complete her Masters of Education. During this time she was surprised that her reflections about education consistently drifted back to her childhood and to her early years as a teacher, providing glimpses of the undeniable connections reaching forward in time to her present beliefs as an educator. Upon her return to the elementary classroom, she has worked hard to remain true to these connections. 